\title{
Evaluation of the operating potential window of electrochemical capacitors
}

\author{
Maksim Bahdanchyk*, Mazdak Hashempour ${ }^{1}$, Antonello Vicenzo ${ }^{1}$
}

Dipartimento di Chimica, Materiali e Ingegneria Chimica “G. Natta”, Politecnico di Milano, Via Luigi Mancinelli 7, 20131 Milano, Italy

\footnotetext{
* Corresponding author. Tel.: +39 02 23993120; fax: +39 02 23993180. E-mail address: maksim.bahdanchyk@polimi.it (M. Bahdanchyk)

${ }^{1}$ ISE Member
}

\begin{abstract}
Widening of the operating potential window is a straightforward route towards increasing the specific energy of electrochemical capacitors. Usually, the assessment of the viable potential range is committed to thermodynamic considerations over the electrolyte potential window and experimental probing of the electrochemical stability of both electrolyte and electrode materials through cyclic voltammetry. However, while the former approach is too conservative, the latter is prone to failure. In the present work, we consider quantitative approaches for monitoring the influence of the potential window on the dissipative behaviour of aqueous electrochemical capacitors. For proving the concept underlying this work, we analyse as a case study an asymmetric cell with a reduced graphene oxide / $\mathrm{MnO}_{2}$ positive electrode and a carbon nanotube based negative electrode, as well as nominally symmetric cells assembled with either electrode. We apply and compare different procedures to define the safe potential window of these systems: the usual potential window opening technique, applied either to single electrodes or packed cells; and not conventional methods, based on the analysis of either the energy efficiency or the cell impedance as a function of the cell
\end{abstract}


potential. Precisely, we analyse the trend of the energy efficiency, derived from galvanostatic charge / discharge experiments, and that of the real component of the cell impedance vs. the potential window, to discriminate the onset of irreversible processes leading to dissipative losses. The viability of the proposed methods and the reliability of the attendant criteria are finally checked in the light of the results of cycling performance of the asymmetric cell.

Keywords: Potential window; Aqueous electrolyte; Asymmetric electrochemical capacitor; Energy efficiency; Electrochemical Impedance Spectroscopy. 


\section{Introduction}

Electrochemical capacitors (EC) are energy storage devices having a specific set of characteristics, such as: higher capacitance and energy density compared with electrolytic and conventional capacitors, higher rate capability and power density compared with batteries, and unmatched long cycle life [1]. The capability to provide high power support and the excellent life expectancy are the main drivers of the commercial expansion of ECs, which are in fact increasingly used in a diverse number of applications, including power electronics [2], renewable energy systems, hybrid energy storage [3], and hybrid and electric vehicles [4]. A critical limitation for ECs, and therefore a major obstacle against further expanding the range of their applications, is the low energy density, E, particularly when compared to batteries [5]. The main restrictions over the achievable energy density are imposed by the electrode capacitance, $C$, and by the operating potential window (PW), $U$, as follows from the expression $E=1 / 2 C U^{2}$. The development of materials with higher specific capacitance and the enlargement of the working PW, achieved thanks to either new electrode materials -of wider capacitive potential range- or novel electrolytes -of wider stable potential range-, can obviously improve the energy performance of ECs [6].

In aqueous electrolytes, a strong constrain over the width of the usable PW is the susceptibility of carbon to oxidation and, more generally, the limited electrochemical stability of water (disregarding here the concern about corrosion susceptibility of current collectors like aluminium or stainless steel in real devices). These inherent limitations have been tackled by a two-fold strategy, based on the adoption of asymmetric cell configuration and a wise choice of the electrode materials [7-8], not to mention the recent advent of so-called "waterin-salt” electrolytes [9].

Manganese dioxide $\left(\mathrm{MnO}_{2}\right)$, as an abundant and inexpensive material with a high theoretical specific capacitance [10], has been widely used in the design of asymmetric cells [11], since 
the early works of Hong et al. [12] and Brousse et al. [13]. Typically, $\mathrm{MnO}_{2}$ is used as the positive electrode coupled to a carbon-based negative electrode, such as activated carbon (AC) [14], reduced graphene oxide (RGO) [15], or carbon nanotubes (CNTs) [16], though recent studies target complex oxide, e.g. [17], or sophisticated material combinations, e.g. [18]. The maximum polarizing potential of an $\mathrm{MnO}_{2}$ electrode is determined by the irreversible oxidation of $\mathrm{Mn}(\mathrm{IV})$ to $\mathrm{Mn}(\mathrm{VII})$, while the low potential limit is dictated by its susceptibility to reduction and dissolution as Mn(II) [19]. Accordingly, in a neutral aqueous electrolyte, the $\mathrm{PW}$ of an $\mathrm{MnO}_{2}$ electrode is about $0.7 \mathrm{~V}$ and its combination with a negative carbon electrode allows widening of the PW to values in the range from $1.5 \mathrm{~V}$ to $2 \mathrm{~V}$, see e.g. [16, 20], and in particular up to $1.8 \mathrm{~V}$ [21-24] (see also [7] for a summary of results). The assessment of the potential range of electrochemical stability is certainly a basic requirement for aqueous asymmetric capacitors and has become, at least in recent times, a key element of the experimental description of asymmetric capacitive storage systems. Nonetheless, notwithstanding the spreading awareness of the compelling need to define the electrochemical stability window in a reliable way, the number of studies addressing this concern is not large.

Usually, the PW of asymmetric ECs is identified by a simple Cyclic Voltammetry (CV) method, based on the qualitative inspection of a series of voltammograms, performed at single electrodes, obtained by incrementally increasing / decreasing the vertex potential of the sweep range, also named potential window opening measurements. The limits of the potential range are identified based on the appearance of specific features in the CV curves pointing to the onset of faradaic processes, e.g. [25]. Then, for the effective operational implementation of the PW, i.e. the achievement of its maximum value, the mass ratio of the electrodes is adjusted to ensure compliance with the charge balance principle [26], according to equation (1) 
$\frac{m_{+}}{m_{-}}=\frac{C_{-} \Delta E_{-}}{C_{+} \Delta E_{+}}$

where $m$ is the mass of the positive or negative electrode, $\Delta E$ is the potential range for charge / discharge and $C$ is the specific capacitance over the corresponding potential range. Notwithstanding the fact that the mass balance criterion, while being widely accepted as ideally sound and rationale, requires practically an empirical correction [27] and should probably be re-examined critically, as recently pointed out [28], there are more and more examples in the literature where this type of approach, combining potential opening and charge balance, has been used [22, 29-32].

$\mathrm{Xu}$ et al. [33-34] first proposed a quantitative method for the assessment of the electrochemical stability limits of ECs. This method is based on the above mentioned CV technique, and relies on coulombic efficiency as the stability criterion. For any given PW value, the factor $S$ (stability, as renamed in [35]) is determined according to equation (2),

$S=\frac{Q_{\text {charge }}}{Q_{\text {discharge }}}-1$

where $Q_{\text {charge }}$ and $Q_{\text {discharge }}$ are the charges stored / released during the positive and negative sweep, respectively. Then, the safe operating potential range for each electrode is derived as the largest potential range where $S<0.1$. The threshold $S=0.1$ corresponds to a faradaic contribution of $10 \%$. The method proposed by Xu et al. was later re-examined and reformulated by Weingarth et al. [35], who introduced the second derivative of S vs. the vertex potential $\frac{d^{2} S}{d U^{2}}$ as a new stability criterion, claiming that the threshold potential could be identified by the condition $\frac{d^{2} S}{d U^{2}}<0.05$. While providing a quantitative procedure for the 
identification of potential limits, both these methods, as the authors themselves recognized, are based on the presumption that the stability of the system will be compromised under some specifically defined conditions, which -however reasonable and practically relevant- remain arbitrary. This suggests that both methods, and possibly any method of a similar kind, cannot guarantee the validity of their outcome, being undermined by a degree of arbitrariness. As a result, since the general principle holds that high values of the operating potential are a primary cause of reduced cycle life, the unambiguous confirmation of the stability of supercapacitors cannot be reached but by long-term cycling or constant potential aging experiments, as underlined in [6, 27] and [36], respectively.

Nevertheless, the use of these methods has gained attention recently, e.g. [37-40], suggesting that there is an increasingly wider recognition of their value compared to the ordinary use of voltammetry for the investigation of electrolyte stability. Still, the evaluation of the operating potential of capacitive storage devices should be committed to meaningful and reliable experimental methods.

In view of the above summary and comments, we remark that the process of defining and validating the operating PW of ECs remains open to scrutiny, in need of further analysis and wider consideration. The present work addresses this need and intends to examine alternative procedures as quantitative diagnostic tools for the evaluation of the safe operating PW of ECs. To this purpose, we use different electrochemical techniques to explore the influence of the PW on key parameters of EC cells, in particular of an asymmetric EC with an RGO/MnO 2 composite as the positive electrode and CNTs as the negative electrode.

We emphasize that the exclusive concern of this work was the comparative assessment of different methods for the evaluation of the PW of EC cells. In particular, neither the optimization of cell performance nor the comparative analysis of the different cells was an objective of the present work. In fact, our purpose is the assessment of the methods, not the 
determination of the maximum PW and the relevant optimization of cell performance. Apparently, the expediency or the unfitness of such methods should be unrelated to the specific operating conditions of any particular cells. Accordingly, we did not attempt to achieve the largest possible PW of the cell through the adjustment of the electrode mass ratio. Rather, we used EC cells assembled with electrodes of similar mass and applied the different methods to assess the PW of the assembled cells after conditioning. The methods for the evaluation of the PW include the following: cyclic voltammetry at increasing vertex potential, applied to both single electrodes -as originally proposed by Xu et al. [33]- and packed cells; probing of the energy efficiency change as a function of the PW; the determination of the real component of the complex impedance, $Z(\omega)$-at the low-end frequency-again as a function of the PW; and, finally, limited to the case study of the asymmetric cell, cycle testing over different PWs in the range of interest.

\section{Materials and Methods}

\subsection{Materials}

CNT were prepared by catalytic growth on a metallic iron-based catalyst supported on $\gamma$ alumina in fluidized bed CVD reactor at $650{ }^{\circ} \mathrm{C}$ using $\mathrm{C}_{2} \mathrm{H}_{4}$ as the carbon precursor, as described in [41]. RGO was obtained by thermal reduction of Graphene Oxide (GO) prepared by the Hummer's method [42], with some modifications as reported in a previous paper [43]. The thermal reduction was performed in a tubular furnace at atmospheric pressure and 600 ${ }^{\circ} \mathrm{C}$, under a mixed flow of $100 \mathrm{sccm} \mathrm{N}$, 100 sccm $\mathrm{H}_{2}$ and $20 \mathrm{sccm} \mathrm{C}_{2} \mathrm{H}_{4}$. Analytical grade $\mathrm{MnO}_{2}$ was purchased from Carlo Erba and used as received.

\subsection{Microstructural and physical characterization}


Phase analysis of raw powders was performed by X-ray diffraction (XRD), with an 1830 PW Philips X-ray generator equipped with a PW 3020 Philips goniometer and a PW 3710 control unit, using the $\mathrm{Cu} \mathrm{K} \alpha$ radiation $(\lambda=1540 \AA)$. Thermo-gravimetric analysis (TGA) was performed in air from $30{ }^{\circ} \mathrm{C}$ to $900{ }^{\circ} \mathrm{C}$ at a heating rate of $10^{\circ} \mathrm{C} \mathrm{min}^{-1}$ using a PerkinElmer Simultaneous Thermal Analyser (STA 600). Nano and microstructure of the active materials were analysed by transmission electron microscopy (TEM) using a Philips CM200 FEG instrument equipped with a field emission Schottky type electron gun operated at $200 \mathrm{kV}$ and by scanning electron microscopy (SEM) using a Stereoscan 360 Cambridge instrument. The electrical conductivity measurements of the powders were carried out using a lab-made cell, as described in a previous paper [43].

\subsection{Electrode fabrication}

Electrode preparation was based on a paste method, using PTFE as the binder and carbon black (TIMCAL C-NERGYTM SUPER C65) as the conductivity promoter, if needed. The active material(s) of interest was mixed with the above components and isopropyl alcohol (IPA), sonicated and homogenized in a mortar to form a paste. The paste was then rolled on a glass plate resulting in a thin freestanding paper. Electrodes of the desired size were cut out from the foil stuck onto a graphite current collector using a conductive adhesive (E-dag $\left.{ }^{\circledR}\right)[44]$.

Two paste types were prepared, namely, CNT and RGO/MnO 2 composite (hereafter referred to as M.RGO). The CNT paste consisted of $90 \mathrm{wt}$ \% CNT and $10 \mathrm{wt} . \%$ PTFE, without conductive carbon. The M.RGO paste was prepared by physical mixing of the components with the following composition: 61 wt.\% RGO, 12 wt.\% $\mathrm{MnO}_{2}$, 19 wt.\% conductive carbon and 8 wt.\% PTFE. 


\subsection{Electrochemical characterization}

The electrochemical characterization was carried out either in a three electrode (single electrode) or in a two-electrode (packed cell) configuration. In all cases, before performing the relevant measurements, as detailed below, the electrodes were soaked in the electrolyte overnight. All electrochemical measurements were performed using a ModuLab ${ }^{\circledR}$ XM ECS potentiostat / galvanostat system (Solartron Analytical XM PSTAT 1 MS/s), equipped with a frequency response analyzer (Solartron Analytical XM FRA 1MHz).

In the three-electrode set up, we used a saturated calomel electrode (SCE) as the reference electrode (the potential is then reported with respect to the standard hydrogen electrode, SHE, with $E_{S C E}=+244 \mathrm{mV}$ SHE), a platinum foil as the counter electrode and the fabricated electrodes as the working electrode, in a $1 \mathrm{M} \mathrm{Na}_{2} \mathrm{SO}_{4}$ electrolyte. CV measurements were performed over a variable potential range, sweeping the potential from the OCP to either the positive or negative direction at the scan rate of $5 \mathrm{mV} \mathrm{s}^{-1}$, and increasing the absolute value of the vertex potential of each successive cycle in step of $50 \mathrm{mV}$.

As the two-electrode configuration, we used a flat cell consisting of two gold / nickel-coated copper current collectors and a PTFE body. The electrodes, prepared according to the aforementioned procedure, were punched out in the form of $12 \mathrm{~mm}$ circular discs and, along with the separator (cellulose-type papers, thickness $50 \mu \mathrm{m}$ ), were soaked for a few hours in the electrolyte $\left(1 \mathrm{M} \mathrm{Na}_{2} \mathrm{SO}_{4}\right)$ before assembling the cell. Two symmetric configurations, namely symmetric CNT (S.CNT, mass loading of about $9 \mathrm{mg} \mathrm{cm}^{-2}$ ) and symmetric M.RGO (S.M.RGO, mass loading of about $5 \mathrm{mg} \mathrm{cm}^{-2}$ ), and an asymmetric configuration, having CNT as the negative and M.RGO as the positive electrode (-CNT-M.RGO ${ }^{+}$, with mass loading of about $6 \mathrm{mg} \mathrm{cm}^{-2}$ for both electrodes), were characterized. Before performing the measurements detailed in the following, the cells were cycled for 200 cycles over the PW of 1 
$\mathrm{V}$, at the scan rate of $100 \mathrm{mV} \mathrm{s}^{-1}$, then subjected to EIS analysis at open circuit, and finally to $\mathrm{CV}$ at $5 \mathrm{mV} \mathrm{s}^{-1}$ scan rate over the potential range from 0 to $1 \mathrm{~V}$ for three cycles.

For the evaluation of the PW of the EC cells we used three different methods: cyclic voltammetry (CV), galvanostatic Charge-Discharge (CD) and Electrochemical Impedance Spectroscopy (EIS).

We applied the CV method to both single electrodes and packed cells, according to the usual procedure [33-34]. The potential of single electrodes was scanned from open circuit to a variable vertex value, either in the positive or negative direction, at the scan rate of $5 \mathrm{mVs}^{-1}$, in three successive cycles for each value of the vertex potential. The specific capacitance of the electrode, $C_{\mathrm{S}}\left(\mathrm{F} \mathrm{g}^{-1}\right)$, was derived as $C_{S}=\frac{Q}{\Delta E \times m}$, where $Q=\int I d E / 2 v$ is the voltammetric charge, calculated as half the ratio of the current (I) integral over the anodic and cathodic sweep and the scan rate $(v), m$ is the mass of active material (including binder and conductive carbon, if present) and $\Delta E$ is the width of the potential sweep range. With the packed cells, the CV method was applied using the same scan rate and procedure, with a variable vertex potential in the range from 1 to $2 \mathrm{~V}$.

The EIS and CD based methods were applied exclusevely to the packed cells. In the CD method, the EC was charged up to different potential values, namely: 1, 1.2, 1.5, 1.7, 1.8 and $2 \mathrm{~V}$, at $1 \mathrm{~A} \mathrm{~g}^{-1}$, followed by discharge at the same rate. The CD method was also used to study the cycling behaviour of the asymmetric EC $\left({ }^{-} \mathrm{CNT}-\mathrm{M} . \mathrm{RGO}^{+}\right)$by charge-discharge at the specific current of $2.5 \mathrm{Ag}^{-1}$ to a variable $\mathrm{PW}$ in the range from 1.5 to $2 \mathrm{~V}$. Capacitance calculation from galvanostatic CD measurements was performed by integration [45], i.e. by direct estimation of the specific energy referred to the total mass of the electrodes according to equation (3):

$$
E_{S}=\frac{I_{d i s} \int_{0}^{t} U_{d i s}(t) d t}{m_{\text {total }}}
$$


where $E_{s}$ is the specific energy, $\int_{0}^{t} U_{d i s}(t) d t$ is the area under the discharge curve, $I_{d i s}$ is the discharge current, $m_{\text {total }}$ is the total mass of the electrodes, including binder and conductive carbon, if present. Then, the specific capacitance $(C S)$ was calculated based on equation (4), where $\Delta U_{\text {dis }}$ is the effective discharge potential after the ohmic drop:

$E_{s}=\frac{1}{8} C_{s} \Delta U_{d i s}^{2}$

The Energy Efficiency (EE) of the cells was calculated according to equation (5) [45].

$E E=\frac{A_{\text {dis }}}{A_{\text {char }}} \times 100=\frac{I_{\text {dis }} \int_{0}^{t} U_{\text {dis }}(t) d t}{I_{\text {char }} \int_{0}^{t} U_{\text {char }}(t) d t} \times 100$

where $A_{\text {char }}$ and $A_{\text {dis }}$ are the areas under charge and discharge curves, respectively. The term

$I \int_{0}^{t} U(t) d t$, corresponds to the integral of the potential trace (either charging or discharging) over the corresponding cycle. In the EIS method, spectra were collected at different cell potential, namely: 0, 0.5, $1 \mathrm{~V}$ and then, with incremental steps of $100 \mathrm{mV}$, up to $2 \mathrm{~V}$. EIS measurements were performed using a sinusoidal excitation signal of $10 \mathrm{mV}$ amplitude, in the frequency range from $100 \mathrm{kHz}$ to $5 \mathrm{mHz}$, sampling 10 points per decade. All EIS measurements were tested for compliance with the Kramers-Kronig relations [46].

\section{Results and Discussion}

\subsection{Microstructural characterization}

Nano- and microstructural characterization results of the active materials are shown in Fig. 1. According to TEM observations in Fig. 1a, CNTs have a homogeneous diameter distribution 
in the range $10-15 \mathrm{~nm}$, with 10 to 20 walls and an interplanar spacing of $3.4 \AA$. Fig. $1 \mathrm{~b}$ shows the thin RGO sheets with typical folding and wrinkling features. TEM micrographs of $\mathrm{MnO}_{2}$ particles (Fig. 1c) reveal two morphologies: nanosize discs with an average diameter of $95 \mathrm{~nm}$ and fibres with diameter around $15 \mathrm{~nm}$ and length in the range of 100 to $200 \mathrm{~nm}$. By high resolution TEM two interplanar spacing can be determined; $3.8 \AA$ corresponding to (110) planes of ramsdellite and $2.4 \AA$ corresponding to (101) planes of pyrolusite.

Phase structure and crystallinity of the starting materials were analysed by XRD as shown in Fig. 1d. The pattern of a pure graphite powder is also reported for comparison purposes. The main peaks of hexagonal graphite ( $\mathrm{P}_{3} / \mathrm{mmc}$ space group) are observed at $26.54^{\circ}, 42.32^{\circ}$ and 44.52 , related to (002), (100) and (101) planes, respectively (COD ID 9011577 [47]). Additionally, two less pronounced peaks at $43.45^{\circ}$ and $46.32^{\circ}$ could be indexed as the (101) and (012) planes, respectively, of rhombohedral graphite, ( $\mathrm{R} \overline{3} m$ space group, COD ID 1200018 and ICDD reference code 01-075-2078 [48]). CNTs match well with the $\mathrm{P} 6_{3} / \mathrm{mmc}$ space group hexagonal graphite. There is a minor shift in the position of (002) planes peak, due supposedly to the slightly larger interplanar spacing of these planes in CNTs (i.e., $3.40 \AA$ compared with $3.35 \AA \AA$ in graphite). The featureless pattern of RGO demonstrates a high degree of exfoliation [49-50]. Additionally, the absence of the characteristic peak of GO, usually observed at $2 \theta$ about $10^{\circ}$, confirms the effectiveness of the thermal reduction process. The $\mathrm{MnO}_{2}$ powder shows a relatively strong peak at $22.077^{\circ}$ which corresponds to the (110) plane of the orthorhombic structure of ramsdellite (ICDD reference code 01-072-1983 [51]). In addition, it shows three peaks at $37.44^{\circ}, 42.82^{\circ}$ and $56.40^{\circ}$ corresponding to (101), (111) and (211) planes, respectively, of the tetragonal pyrolusite structure, belonging to $\mathrm{P} 4_{2} / \mathrm{mnm}$ space group (ICDD reference code 00-004-0779 [52]). Accordingly, both the TEM observations, i.e., the presence of two phases and their particular orientations, are confirmed 
via XRD. The relative content of the two phases in $\mathrm{MnO}_{2}$, calculated using the Rietveld refinement method, was about $90 \%$ ramsdellite and $10 \%$ pyrolusite.

Carbon materials were analysed for purity and thermal stability by TGA (Fig. 1e). The purity of both CNT and RGO was confirmed by the negligible ash content. The inflection point of the weight loss curve, corresponding to the main combustion temperature, was at $619^{\circ} \mathrm{C}$ for CNTs compared with $607^{\circ} \mathrm{C}$ for RGO, demonstrating the slightly higher thermal stability of CNTs. The weight loss of less than $10 \%$ before $450{ }^{\circ} \mathrm{C}$ for RGO, mainly due to water evaporation and dissociation of unstable oxygen functional groups, suggests that a major part of oxygen was removed from GO in the process of thermal reduction.

\section{Fig. 1}

Fig. If shows the electrical conductivity of the powders as a function of the applied pressure. The conductivity value at the plateau region of maximum powder compaction is used for comparison. CNTs reached the highest conductivity among other samples, namely, $590 \mathrm{~S} \mathrm{~m}^{-1}$, which is the closest value to the graphite control sample $\left(685 \mathrm{~S} \mathrm{~m}^{-1}\right)$, while $\mathrm{MnO}_{2}$ powders, expectably, possessed the lowest conductivity of $30 \mathrm{mS} \mathrm{m}^{-1}$. The conductivity of RGO was about $1 \mathrm{~S} \mathrm{~m}^{-1}$ under the maximum pressure. Considering the relatively good reduction level confirmed for this sample by XRD and TGA, such moderate level of the electrical conductivity is probably due to incomplete recovery of the damaged graphitic structure. SEM micrograph of the CNT electrode shows a relatively flat surface with numerous pores at low magnification (Fig. 2a), while at higher magnification (Fig. 2b), the flat regions appear to be composed of compact aggregates of spaghetti like filaments. The M.RGO paste looks more compact than the CNT paste at low magnification (Fig. 2c) without clear sign of $\mathrm{MnO}_{2}$ particles. At higher magnification however (Fig. 2d), not only the wrinkled and folded 
appearance of the RGO sheets is apparent, but it is also possible to distinguish $\mathrm{MnO}_{2}$ particles (indicated by the black arrow) dispersed between RGO flakes. Additionally, PTFE fibres can be seen in both pastes as shown by white arrows.

Fig. 2

\subsection{Electrochemical characterization}

In this section, we report the results of the cyclic voltammetry study of the single electrodes: i.e., the CNT and M.RGO electrode; and of three packed cells, namely: the nominally symmetric CNT (S.CNT) and M.RGO cells (S.M.RGO) and the asymmetric cell with a negative CNT electrode and a positive M.RGO electrode (-CNT-M.RGO ${ }^{+}$).

\subsubsection{Cyclic voltammetry}

In the following, we evaluate the potential window of the packed cells applying the S-value method to both single electrodes and packed cells, according to the 0.1 threshold value criterion [34].

The graphs in Fig. 3a-c show the results of the CV characterization of the single electrodes, namely M.RGO, CNT and CNT negative / M.RGO positive electrodes, respectively, together with the corresponding S-value -as defined in equation (2)- and specific capacitance of the electrodes vs. the CV potential sweep range. Before detail discussion of these results, we observe that, on positive polarization, a current leap is visible at high enough potential values in the CV curves of both M.RGO and CNT electrodes, namely at potential above about $0.9 \mathrm{~V}$ SHE and 1.0 V SHE, respectively. At such potential, the faradaic process associated with the current leap is the oxidation of surface functionalities of carbon [53] and the lower on-set potential for the M.RGO electrode obviously correlates with the comparatively lower purity 
and crystallinity of RGO vs. CNT. The oxidation of carbon to $\mathrm{CO}_{2}$ will occur at higher potential [53-54], and will precede or overlap with the oxygen evolution reaction [53,55-56], so that we can assume that either reaction may contribute to faradaic charge transfer only at the extreme of the positive potential range of Fig. 3. Of course, the M.RGO electrode is also prone to irreversible charge transfer by the oxidation of $\mathrm{Mn}(\mathrm{IV})$ to $\mathrm{Mn}(\mathrm{VII})$, as noted previously, at potential in excess of 1.1 V SHE.

With regard to the evaluation of the PW from the single electrode analysis, we observe that, since the packed cells have the same mass loading at the negative and positive electrode, the charge balance constraint translates into the condition: $\Delta E_{+} / \Delta E_{-}=C_{-} / C_{+}$.

The visual examination of the CV curves shown in Fig. 3a suggests that the capacitive behaviour of the M.RGO electrode is symmetric vs. the open circuit potential (OCP), $0.465 \pm 0.010 \mathrm{~V}$ vs. SHE. Expectedly, on the positive side, the symmetry is compromised at potential higher than about $1 \mathrm{~V}$ vs. SHE, due to surface oxidation of RGO. Conversely, on the negative side, the rising trend of the negative current at potential below about $0.2 \mathrm{~V} v$ s. SHE, points to the reduction of $\mathrm{MnO}_{2}$ as the faradaic process overlapping capacitive charging [19]. As a matter of fact, a close look to the $C_{s} v s$. potential plot reveals slight differences at the extremes of the range, with $C_{+}$values about $10 \%$ higher than $C_{-}$. Then, since the negative electrode is likely to be the limiting electrode, we assume as the low-end value of the potential window the potential at which the S-value is 0.1 , i.e. $-0.130 \mathrm{~V}$ vs. SHE (which corresponds to $\left.\Delta E_{-} \approx 0.590 \mathrm{~V}\right)$, see Fig. 3a. By plotting the products $C_{-} \cdot \Delta E_{-}$and $C_{+} \cdot \Delta E_{+}$from the data in Fig. 3-a vs. $\Delta E$, see Fig. $3 d$, we can conclude that the highest value of $\Delta E_{+}$, which satisfies the equality $C_{+} \Delta E_{+}=C_{-} \Delta E_{-}$, is $0.550 \mathrm{~V}$. Then, the S-value method applied to the single electrode predicts a potential window of about $1.14 \mathrm{~V}$ for the M.RGO packed cell. As shown by CV curves collected in the plot of Fig. 3b, the charge storage behaviour of the CNT electrode is highly asymmetric, to the extent that the operating potential range of a 
properly mass balanced cell could reach $2.3 \mathrm{~V}$, though with a rather severe mass ratio $m_{+} / m_{-}$ of about 4.5 (by the way, notwithstanding this obvious asymmetry, we will continue to refer to this cell as a symmetric cell in the following). Similarly to the M.RGO electrode, carbon oxidation overlaps with capacitive charging at high potential, while, on negative polarization, the range of potential dominated by capacitive charging extends apparently down to -1.1 vs. SHE, by the pseudocapacitance associated with hydrogen reduction and intercalation, as for activated carbon [57]. The intrinsic asymmetry of the CNT electrode is reflected in the change of $C_{s}$ with potential, and is confirmed by the S-value analysis of CV curves, also shown in Fig. 3b. For the evaluation of the PW of the CNT cell, we use the same procedure as for the M.RGO cell. The CNT positive electrode -which is obviously the limiting electrode- reaches the S-value threshold at the potential of $1.17 \mathrm{~V} v$ s. SHE, corresponding to $\Delta E_{+} \approx 0.67 \mathrm{~V}$ (the OCP of the CNT electrode is about $0.505 \pm 0.005 \mathrm{~V}$ vs. SHE). By the graphical method illustrated in Fig. 3e, we obtain $\Delta E_{-} \approx 0.50 \mathrm{~V}$ and for the PW of the CNT packed cell the value of $1.17 \mathrm{~V}$.

In the plots of Fig. 3c, we show the same set of data for the M.RGO positive electrode and the CNT negative electrode, as already shown in Fig. 3a and Fig. 3b, respectively, to visualize the behaviour of the asymmetric cell ${ }^{-} \mathrm{CNT}-\mathrm{M} . \mathrm{RGO}^{+}$. For this cell, given the wide range of polarizability of the CNT negative electrode, the M.RGO is the limiting electrode. The 0.1 threshold S-value for the positive M.RGO electrode is $1.07 \mathrm{~V}$ vs. SHE, see Fig. 3a, from which we get $\Delta E_{+} \approx 0.61 \mathrm{~V}$. Following the same procedure as above, see Fig. 3f, we find that the maximum negative excursion allowed to the CNT negative electrode is $\Delta E_{-} \approx 0.47 \mathrm{~V}$. Then, according to the S-value method applied to single electrodes, the PW of the ${ }^{-} \mathrm{CNT}$ M.RGO ${ }^{+}$cell is $1.08 \mathrm{~V}$.

As already mentioned at the beginning of this section, we applied the S-value method also to the packed cells, which is an unconventional use of the potential window opening technique, 
obtaining the CV curves, shown in Fig. 4a-c. A common feature of the curves is the sharp rise of the current at the positive end of the potential range -provided the cell potential is in excess of $1.2 \mathrm{~V}$ - though it is more pronounced and has the earliest appearance for the S.M.RGO cell. According to the analysis of the single electrodes behaviour, for the cell potential of $1.2 \mathrm{~V}$ or higher, the potential at the M.RGO positive electrode -given the almost symmetric behaviour of the cell- will be about $1.1 \mathrm{~V}$ vs. SHE or higher, respectively, then within the region of carbon oxidation, see CV curves in Fig. 3a. With regard to the S.CNT and the ${ }^{-}$CNT-M.RGO ${ }^{+}$ cells, the asymmetric nature of their behaviour prevents a confident prediction of the potential of the electrodes. We notice, however, that, at the cell potential of $1.5 \mathrm{~V}$, the current leap associated with carbon oxidation is similar for S.M.RGO and S.CNT cells, but definitely less pronounced for the ${ }^{-}$CNT-M.RGO ${ }^{+}$cell (Fig. 4a-c). These remarks find confirmation in the cell S-values calculated by equation (2) and plotted as a function of the PW in Fig. 4d, showing that the condition $S<0.1$ is violated above $1.04 \mathrm{~V}$ for the S.M.RGO cell, above 1.24 V for the S.CNT cell and above about $1.36 \mathrm{~V}$ for the asymmetric ${ }^{-} \mathrm{CNT}-\mathrm{M} . \mathrm{RGO}^{+}$cell. Significantly, either the absolute values or the rate of increase of the S parameter are higher for the S.M.RGO symmetric cell compared with the S.CNT and the ${ }^{-}$CNT-M.RGO ${ }^{+}$cells, both having an asymmetric nature for different reasons, over the entire PW range.

\section{Fig. 4}

\subsubsection{Energy efficiency}

The Energy Efficiency (EE), a metric representing the cumulative effect of Ohmic, faradaic and diffusive losses, was determined as a function of the PW at the charge-discharge rate of 1 $\mathrm{Ag}^{-1}$. Fig. 5a shows the galvanostatic CD curves of the cells over a variable PW, from 1 to 2 $\mathrm{V}$; the plot of the energy efficiency $v s$. the potential window for the three cells is presented in 
Fig. 5b. The variation of the EE for the S.M.RGO and S.CNT cells shows a similar trend, with marginal changes over the range from 1.0 to $1.5 \mathrm{~V}$, notably a gradual decrease at PW in excess of $1.2 \mathrm{~V}$, followed by a sharp drop at potential higher than $1.5 \mathrm{~V}$. In contrast, the EE of the ${ }^{-} \mathrm{CNT}-\mathrm{M} . \mathrm{RGO}^{+}$asymmetric cell reveals a steady increase up to $1.8 \mathrm{~V}$. Apparently, the extent of the changes of the EE with the PW is limited (suggesting opposing effects of the PW on efficiency), and, because of this evident character, we can already conclude that this approach does not promise to be effective as a tool to evaluate the PW, at least for the EC cells of the present work. Nonetheless, it may be of some interest to comment briefly on the data plotted in Fig. 5b. From these results, it may be inferred that increasing the PW above 1.2 $\mathrm{V}$ will cause a loss of efficiency for both the (nominally) symmetric cells; and that the asymmetric ${ }^{-}$CNT-M.RGO ${ }^{+}$cell does not show an obvious loss of efficiency even when operated over the PW of 1.8 V. The simplest and natural criterion concerning the energy efficiency that we can propose for evaluating the PW of the cells is obviously the achievement of maximum EE. Accordingly, while $1.8 \mathrm{~V}$ may be taken, provisionally, as the PW limit of the asymmetric cell according to this method, the data suggest only a lower value estimate for the PW limit of the S.M.RGO and S.CNT cells, namely 1.2 V. Specifically, we remark that the almost invariant trend of EE vs. PW for the S.M.RGO and S.CNT cells points probably to the balancing of different effects, i.e., on the one end, a relative increase of the dissipative losses associated with faradaic reactions and, on the other hand, the increase of cell capacitance with increasing PW up to about 1.2 V. Conversely, the increasing trend of EE vs. PW for the asymmetric cell suggests a prevalent effect of the increase of cell capacitance, probably depending on the uneven potential distribution between the positive and negative electrode $[27,58]$.

\section{Fig. 5}


However, we emphasize that these results reflect the behaviour of the cell without and/or before any intervening degradation events. We will reconsider critically the significance of these results later on, in the light of the cycle life behaviour of the ${ }^{-} \mathrm{CNT}-\mathrm{M} . \mathrm{RGO}^{+}$cell reported further on in section 3.2.4.

\subsubsection{Electrochemical Impedance Spectroscopy}

A further approach to the evaluation of the PW of EC cells was based on potentiostatic impedance measurements at varying bias, changing the applied potential in steps of $0.1 \mathrm{~V}$ in the range from 1.0 to $2.0 \mathrm{~V}$. The complex plots of the three cells recorded at different potentials are shown in Fig. 6.

The evolution of the spectra with increasing cell potential follows a similar path for all cells, revealing a gradual bending of the low-end frequency as the potential is increased up to $2 \mathrm{~V}$, showing in the complex plot a relatively large circular arc instead of the regular capacitive straight line. Apparently, the determination of a threshold point for this gradual transition is not straightforward. Therefore, since the modification of the spectra points to a rising resistive contribution associated with faradaic charge transfer, we focused on the real component of the complex impedance and plotted its value at the lowest frequency $\left(Z^{\prime}\right.$ at $\left.5 \mathrm{mHz}\right) v s$. the cell potential, as shown in Fig. 6-d. In this representation, a clear transition is observed between two potential regions for all cells, as evidenced by an obvious change in the slope of $Z^{\prime} v s$. PW. Accordingly, the PW limit is determined as the intersection of the lines fitting the data within these potential regions. On this basis, the S.M.RGO cell shows a PW of $1.10 \mathrm{~V}$, the S.CNT cell a PW close to $1.35 \mathrm{~V}$ and the ${ }^{-} \mathrm{CNT}-\mathrm{M} . \mathrm{RGO}^{+}$cell a PW close to $1.50 \mathrm{~V}$.

\section{Fig. 6}


The results of the EIS analysis are compared with the PW estimation derived using the other methods in Table 1. In the following comments, we consider first the results obtained by each method for the three cells, then individually each cell.

In the case of the S.M.RGO and S.CNT cells, the evaluation of the PW by the S-value method gives consistent results, when applied to either single electrodes or packed cells. This is not the case with the asymmetric ${ }^{-} \mathrm{CNT}-\mathrm{M} . \mathrm{RGO}^{+}$cell, for which the difference in the PW value derived from packed cell and single electrode measurements is almost $0.3 \mathrm{~V}$.

The method based on the trend of EE with PW gives relatively high values of the PW limit, in particular for the S.M.RGO and the ${ }^{-}$CNT-M.RGO ${ }^{+}$cell. This apparent overestimation of the PW suggests that the EE method is unable to represent realistically the behaviour of an EC cell in the as-prepared state, after conditioning, but in the absence of aging effects, which expectedly entail significant impact on the energy delivered by the EC. In this regard, we argue that, since the energy efficiency correlates strongly with internal resistance, the trend of the EE with PW is largely determined by ohmic losses. Thus, at low PW, this method lacks the sensitivity required to discriminate comparatively small changes associated with intervening faradaic losses. Conversely, as the PW increases, faradaic losses may be overshadowed by the concomitant increase of the capacitance with PW, at least within a range, as it seems to be the case with the asymmetric cell.

Among the other methods, the EIS based method stands out for providing clear cut evidence of the effect of the PW applied to the EC cells on a fundamental parameter, namely the low frequency impedance, which correlates strongly with the prevalent dissipative factors and has also an obvious bearing on the performance of the device.

A preliminary remark about the evaluation of the PW limit of the different EC cells, as listed in Table 1, is that, as already pointed out in the above comments, the values obtained by the EE based method are apparently unreliable and will be ignored in the following discussion. 
Table 1. Assessed potential window of the EC cells based on different methods.

\begin{tabular}{l|c|l|l|l}
\multirow{2}{*}{ Electrode / Cell } & \multicolumn{4}{|c}{ Potential window limit / V } \\
\cline { 2 - 3 } & \multicolumn{2}{|c|}{ S - value (0.1 threshold) } & \multirow{2}{*}{$\begin{array}{c}\text { Energy } \\
\text { efficiency }\end{array}$} & \multirow{2}{*}{ EIS } \\
\cline { 2 - 3 } & $\begin{array}{l}\text { Single } \\
\text { electrode }\end{array}$ & Cell & 1.2 & 1.10 \\
\hline S.M.RGO & 1.14 & 1.04 & 1.2 & 1.35 \\
S.CNT & 1.17 & 1.24 & 1.8 & 1.50 \\
-CNT-M.RGO & 1.08 & 1.36 & &
\end{tabular}

The spread of the PW limit values is the smallest for the S.M.RGO cell, i.e. $0.1 \mathrm{~V}$; it is intermediate for the S.CNT cell, i.e. $0.18 \mathrm{~V}$; and it is the largest for the asymmetric cell, i.e. $0.42 \mathrm{~V}$. The overall good agreement of the assessed PW values for the S.M.RGO cell points to the high degree of symmetry of the cell, implying that the cell behaviour can be predicted confidently on the basis of the single electrode behaviour. This is not the case with the cells showing a significant degree of asymmetry, namely the S.CNT and ${ }^{-} \mathrm{CNT}-\mathrm{M} . \mathrm{RGO}^{+}$cells. Moreover, the spread of results is apparently larger the stronger is the asymmetry, i.e. the more are the factors determining the asymmetry; in fact, while the asymmetry of the S.CNT cell is eminently of electrochemical nature, due only to different charge storage mechanisms at the opposite electrodes, the asymmetry of the ${ }^{-} \mathrm{CNT}-\mathrm{M} \cdot \mathrm{RGO}^{+}$cell is manifold, including electrochemical and physical properties. This analysis suggests that the potential window opening method applied to single electrodes may lead to erroneous results when used in the assessment of the PW of asymmetric cell. Actually, the values of the PW assessed by the same latter method applied to the packed cell and the EIS based method are in reasonable agreement, for both the S.CNT and ${ }^{-}$CNT-M.RGO ${ }^{+}$cell. 


\subsubsection{Cycle life at variable potential window}

In order to verify the significance and confirm the viability of the above methods for the assessment of the potential window limit, we present and discuss in this section the cycling test of the ${ }^{-}$CNT-M.RGO ${ }^{+}$cell by the galvanostatic CD technique. We performed this analysis on the ${ }^{-}$CNT-M.RGO ${ }^{+}$cell, because this is the more controversial system according to the results reported in the previous section. We assume that the safe PW limit for this cell is about $1.5 \mathrm{~V}$ (i.e., the value determined by the EIS method, based on the trend of the real component of the impedance vs. the cell potential), since this figure is in agreement with several literature reports on $\mathrm{MnO}_{2}$ based asymmetric ECs [20-24]). Precisely, the ${ }^{-} \mathrm{CNT}-\mathrm{M} \cdot \mathrm{RGO}^{+}$was initially tested in the PW of $1.5 \mathrm{~V}$ for 5000 cycles. Then, the PW was increased in steps of $0.1 \mathrm{~V}$ from $1.5 \mathrm{~V}$ up to $2 \mathrm{~V}$, cycling the cell for 1000 cycles at each PW value between $1.6 \mathrm{~V}$ and $2 \mathrm{~V}$. The results of the cycling test are shown in Fig. 7.

\section{Fig. 7}

The capacitance of the ${ }^{-} \mathrm{CNT}-\mathrm{M} . \mathrm{RGO}^{+}$cell increased by 5\% during the first 5000 cycles (Fig. 7-a), a kind of behaviour that has been reported repeatedly for $\mathrm{MnO}_{2}$ based electrodes (see, e.g., our own work [59-60] and references therein). Notably, the gradual increase of $C_{s}$ with cycling was not limited to the PW of $1.5 \mathrm{~V}$, but continued up to the PW of $1.9 \mathrm{~V}$. Then, after 1000 cycles in the PW of $1.9 \mathrm{~V}$ without obvious drop of $C_{s}$, an abrupt decrease occurred during cycling in the PW of $2 \mathrm{~V}$. While in conventional galvanostatic cycle life testing, the preservation or possibly the enhancement of $C_{s}$ are evidence of the state of health of the device, in the present case, the increase of $C_{s}$ is apparently due to the widening of the PW -as obviously revealed by the initial step in the capacitance upon increase of the PW in the range from 1.6 to $1.9 \mathrm{~V}$ - and it is therefore unrelated to the state of health of the cell. This result 
underlines the limit, and possibly the misleading insight, of the wide-spread practice of monitoring only the specific capacitance during cycle-life testing. Furthermore, it is clear that a PW of $2 \mathrm{~V}$ causes a strong acceleration of the mechanisms leading to performance degradation. Besides the trend of the specific capacitance, we also monitored the variation of EE and internal resistance $\left(R_{i n t}\right)$ over cycling as shown in Fig. 7-b. Overall, both parameters display a stable trend during cycling within the PW of $1.5 \mathrm{~V}$, and even a sort of recovery effect when the PW is increased to $1.6 \mathrm{~V}$. However, a decaying or rising trend sets in for EE and $R_{\text {int }}$, respectively, when the cell is cycled in the potential window of $1.7 \mathrm{~V}$. Thereafter, as the PW is increased above the latter value -notwithstanding the jump in the EE (in agreement with section 3.2.2, see Fig. 5) and the corresponding small drop of $R_{\text {int }}$ at each increment of the PW up to $1.8 \mathrm{~V}$ - the trend of EE is decreasing while $R_{\text {int }}$ rises at any increment of the PW beyond $1.6 \mathrm{~V}$. Overall, it is apparent that the cell underwent a fast degradation as the PW was set to $1.7 \mathrm{~V}$; on the other hand, the limited number of cycles does not permit to conclude that the cell could withstand the PW of $1.6 \mathrm{~V}$. At any rate, the cycling test confirms that the ${ }^{-} \mathrm{CNT}$ M.RGO ${ }^{+}$can be operated over the PW of $1.5 \mathrm{~V}$, in agreement with the value predicted by the EIS based method.

Eventually, we observe, in passing, that, since maximizing the PW requires optimization of the electrode mass ratio - which, as noted earlier, was not attempted in this work-, the PW value for the this cell is lower compared with the results of previous reports for similar cells, upon charge balancing, such as in [27], where a PW of $2 \mathrm{~V}$ was demonstrated for a cell with a positive $\mathrm{MnO}_{2}$ and a negative $\mathrm{AC}$ electrode in $\mathrm{NaSO}_{4}$ electrolyte. In principle, based on the results shown in Fig. 3, the potential window of the ${ }^{-} \mathrm{CNT}-\mathrm{M} . \mathrm{RGO}^{+}$asymmetric cell could be as high as $1.8 \mathrm{~V}$ (with $\Delta E_{+} \approx 0.6 \mathrm{~V}$ and $\Delta E_{-} \approx 1.2 \mathrm{~V}$ ) with a mass ratio $m_{+} / m_{-}$of 3 .

With regard to the use of EE as a diagnostic criterion for the evaluation of the PW, as outlined by results shown in Fig. 5, we can now conclude unequivocally that it cannot be accepted. 
Namely, the energy efficiency, as a metric greatly sensitive to the state of health of the device upon ageing, it is not a suitable "stand-alone" criterion for the assessment of the PW.

Conversely, the great sensitivity to potential induced degradation during cycling experiments, qualifies the energy efficiency as an effective indicator of the impact of the PW on the EC cycle life performance, just like the internal resistance [61]. Accordingly, we suggest that the modified cycle life test, performed for a limited number of cycles at increasing level of the cell potential, is also a feasible method for a relatively fast validation of the results obtained by CV or EIS.

\section{Conclusions}

In this work, we examine different approaches for the evaluation of the potential window of electrochemical capacitors. We applied these approaches to both symmetric and asymmetric cell configurations, in particular to an asymmetric cell composed of CNT as the negative and $\mathrm{RGO} / \mathrm{MnO}_{2}$ composite as the positive electrode $\left({ }^{-} \mathrm{CNT}-\mathrm{M} \cdot \mathrm{RGO}^{+}\right)$.

The results of this investigation are summarized as follows.

EIS measurements at varying cell potential in the PW range show a clear-cut change in the trend of $Z^{\prime}$, the real part of the cell impedance, vs. PW. Accordingly, a threshold value marking the transition from the PW region where the cell resistance is either flat or increasing slightly and the PW region of steep rise of the resistance can be determined. Significantly, the prediction of this method for the asymmetric cell is within the safety range ascertained by the CD cycling test.

The energy efficiency can be used as a sensitive parameter in monitoring the cycle life behaviour of ECs, in particular to the purpose of probing the influence of the operating potential on the onset and/or acceleration of degradation mechanisms. In fact, in cycle life experiments, the energy efficiency will decay at unsuitably high values of the PW, even 
though $C_{s}$ may show a sustained rising trend. Conversely, observing the change of the energy efficiency as a function of the PW, in the absence of any significant ageing effects, does not appear as a viable monitoring approach for the determination of the PW.

For a reliable predictive assessment of the PW of asymmetric ECs, a set of different techniques should be used, each with its own diagnostic criterion, since there is no basic principle or clear evidence supporting any particular technique as conclusively reliable. Nonetheless, the method based on EIS proposed in the present work appears to predict clearly and reliably the change of regime in the EC behaviour, from safe to risky. Above all, CD cycling is an effective method to probe the width of the PW, since it provides straightforward evidence of the onset of electrode degradation. In this regard, our results suggest that CD cycling at increasing value of the cell potential or PW, over a relatively limited number of cycles for each PW value, may provide useful indications about the maximum operating potential of an EC. 


\section{References}

[1] J.R. Miller and A.F. Burke, Electrochemical Capacitors: Challenges and Opportunities for Real-World Applications, Interface 17 (2008) 53-57.

[2] N. Kularatna, ed., Energy Storage Devices for Electronic Systems, Academic Press, 2015. https://doi.org/10.1016/C2012-0-06356-9.

[3] L. Zhang, X. Hu, Z. Wang, F. Sun, D.G. Dorrell, A review of supercapacitor modelling, estimation, and applications: A control/management perspective, Renewable Sustainable Energy Rev. 81 (2018) 1868-1878. https://doi.org/10.1016/j.rser.2017.05.283.

[4] A. Burke, Z. Liu and H. Zhao, Present and future applications of supercapacitors in electric and hybrid vehicles, 2014 IEEE International Electric Vehicle Conference (IEVC), Florence, 2014, 1-8. https://doi.org/10.1109/IEVC.2014.7056094.

[5] B.E. Conway, "Similarities and Differences between Supercapacitors and Batteries for Storing Electrical Energy”, in Electrochemical Supercapacitors, Springer, US, Boston, 1999, Ch. 2, pp. 11-31. https://doi.org/10.1007/978-1-4757-3058-6_2.

[6] M. Yu, Y. Lu, H. Zheng, X. Lu, New Insights into the Operating Voltage of Aqueous Supercapacitors, Chem. Eur. J. 24 (2018) 3639-3649. https://doi.org/0.1002/chem.201704420.

[7] Y. Shao, M. F. El-Kady, J. Sun, Y. Li, Q. Zhang, M. Zhu, H. Wang, B. Dunn, and R. B. Kaner, Design and Mechanisms of Asymmetric Supercapacitors, Chem. Rev. 118 (2018) 9233-9280. https://doi.org/10.1021/acs.chemrev.8b00252.

[8] N. Choudhary, C. Li, J. Moore, N. Nagaiah, L. Zhai, Y. Jung, J. Thomas, Asymmetric Supercapacitor Electrodes and Devices, Adv. Mater. 29 (2017) 1605336. https://doi.org/10.1002/adma.201605336.

[9] L. Suo, O. Borodin, T. Gao, M. Olguin, J. Ho, X. Fan, C. Luo, C. Wang, K. Xu, "Water-in-salt" electrolyte enables high-voltage aqueous lithium-ion chemistries, Science 350 (2015) 938-943. https://doi.org/10.1126/science.aab1595.

[10] W. Wei, X. Cui, W. Chen, D.G. Ivey, Manganese oxide-based materials as electrochemical supercapacitor electrodes, Chem. Soc. Rev. 40 (2011) 1697-1721. https://doi.org/10.1039/C0CS00127A. 
[11] J.-G. Wang, F. Kang, B. Wei, Engineering of $\mathrm{MnO}_{2}$-based nanocomposites for highperformance supercapacitors, Prog. Mater. Sci. 74 (2015) 51-124. https://doi.org/10.1016/j.pmatsci.2015.04.003.

[12] M.S. Hong, S.H. Lee, and S.W. Kim, Use of KCl Aqueous Electrolyte for $2 \mathrm{~V}$ Manganese Oxide/Activated Carbon Hybrid Capacitor, Electrochem. Solid-State Lett. 5 (2002) A227-A230. https://doi.org/10.1149/1.1506463.

[13] T. Brousse, M. Toupin, and D. Bélanger, A Hybrid Activated Carbon-Manganese Dioxide Capacitor using a Mild Aqueous Electrolyte, J. Electrochem. Soc. 151 (2004) A614-A622. https://doi.org/10.1149/1.1650835.

[14] V. Khomenko, E. Raymundo-Piñero, F. Béguin, Optimisation of an asymmetric manganese oxide/activated carbon capacitor working at $2 \mathrm{~V}$ in aqueous medium, $\mathrm{J}$. Power Sources 153 (2006) 183-190. https://doi.org/10.1016/j.jpowsour.2005.03.210.

[15] Z.-S. Wu, W. Ren, D.-W. Wang, F. Li, B. Liu, and H.-M. Cheng, High-Energy $\mathrm{MnO}_{2}$ Nanowire/Graphene and Graphene Asymmetric Electrochemical Capacitors, ACS Nano 4 (2010) 5835-5842. https://doi.org/10.1021/nn101754k.

[16] J. Hao, Li Chunzhong, S. Ting and Ma Jan, A green and high energy density asymmetric supercapacitor based on ultrathin $\mathrm{MnO}_{2}$ nanostructures and functional mesoporous carbon nanotube electrodes, Nanoscale 4 (2012) 807-812. https://doi.org/10.1039/C1NR11542A.

[17] J. Li, L. An, H. Li, J. Sun, C. Shuck, X. Wang, Y. Shao, Y. Li, Q. Zhang, H. Wang, Tunable stable operating potential window for high-voltage aqueous supercapacitors, Nano Energy, 63 (2019) 103848. https://doi.org/10.1016/j.nanoen.2019.06.044.

[18] G. Zhang, H. Yao, F. Zhang, Z. Gao, Q. Li, Y. Yang, X. Lu, A high over-potential binder-free electrode constructed of Prussian blue and $\mathrm{MnO}_{2}$ for high performance aqueous supercapacitors, Nano Res. 12 (2019) 61-69. https://doi.org/10.1007/s12274019-2347-2.

[19] M. Pourbaix, Atlas d'équilibres électrochimiques, Gauthier-Villars, Paris 1963, pp. 286-293.

[20] A. Sumboja, C.Y. Foo, X. Wang, P.S. Lee, Large areal mass, flexible and freestanding reduced graphene oxide/manganese dioxide paper for asymmetric supercapacitor device, Adv. Mater. 25 (2013) 2809-2815. https://doi.org/10.1002/adma.201205064.

[21] T. Zhai, F. Wang, M. Yu, S. Xie, C. Liang, C. Li, F. Xiao, R. Tang, Q. Wu, X. Lu, Y. Tong, 3D $\mathrm{MnO}_{2}$-graphene composites with large areal capacitance for high- 
performance asymmetric supercapacitors, Nanoscale 5 (2013) 6790-6796. https://doi.org/10.1039/c3nr01589k.

[22] Z. Fan, J. Yan, T. Wei, L. Zhi, G. Ning, T. Li, Asymmetric Supercapacitors Based on Graphene / $\mathrm{MnO}_{2}$ and Activated Carbon Nanofiber Electrodes with High Power and Energy Density, Adv. Funct. Mater. 21 (2011) 2366-2375. https://doi.org/10.1002/adfm.201100058.

[23] Y. Shao, H. Wang, Q. Zhang, Y. Li, High-performance flexible asymmetric supercapacitors based on 3D porous graphene/ $\mathrm{MnO}_{2}$ nanorod and graphene/Ag hybrid thin-film electrodes, J. Mater. Chem. C. 1 (2013) 1245-1251. https://doi.org/10.1039/C2TC00235C.

[24] J. Chang, M. Jin, F. Yao, T.H. Kim, V.T. Le, H. Yue, F. Gunes, B. Li, A. Ghosh, S. Xie, Y.H. Lee, Asymmetric supercapacitors based on graphene $/ \mathrm{MnO}_{2}$ nanospheres and graphene/ $\mathrm{MoO}_{3}$ nanosheets with high energy density, Adv. Funct. Mater. 23 (2013) 5074-5083. https://doi.org/10.1002/adfm201301851.

[25] Z.-S. Wu, W. Ren, D.-W. Wang, F. Li, B. Liu, H.-M. Cheng, High-Energy $\mathrm{MnO}_{2}$ Nanowire/Graphene and Graphene Asymmetric Electrochemical Capacitors, ACS Nano 4 (2010) 5835-5842. https://doi.org/10.1021/nn101754k.

[26] J.P. Zheng, The Limitations of Energy Density of Battery/Double-Layer Capacitor Asymmetric Cells, J. Electrochem. Soc., 2003 150(4): A484-A492. https://doi.org/10.1149/1.1559067

[27] L. Demarconnay, E. Raymundo-Piñero, F. Béguin, Adjustment of electrodes potential window in an asymmetric carbon/ $\mathrm{MnO}_{2}$ supercapacitor, J. Power Sources 196 (2011) 580-586. https://doi.org/10.1016/j.jpowsour.2010.06.013.

[28] Z. Dai, C. Peng, J.H. Chae, K.C. Ng, G.Z. Chen, Cell voltage versus electrode potential range in aqueous supercapacitors, Scientific Report 5 (2015) 9854. https://doi.org/10.1038/srep09854.

[29] L. Demarconnay, E. Raymundo-Piñero, F. Béguin, A symmetric carbon/carbon supercapacitor operating at $1.6 \mathrm{~V}$ by using a neutral aqueous solution, Electrochem. Commun. 12 (2010) 1275-1278. https://doi.org/10.1016/j.elecom.2010.06.036.

[30] Y.K. Hsu, Y.C. Chen, Y.G. Lin, L.C. Chen, K.H. Chen, High-cell-voltage supercapacitor of carbon nanotube/carbon cloth operating in neutral aqueous solution, J. Mater. Chem. 22 (2012) 3383-3387. https://doi.org/10.1039/c1jm14716a. 
[31] Z. Lei, J. Zhang, X.S. Zhao, Ultrathin $\mathrm{MnO}_{2}$ nanofibers grown on graphitic carbon spheres as high-performance asymmetric supercapacitor electrodes, J. Mater. Chem. 22 (2012) 153-160. https://doi.org/10.1039/c1jm13872c.

[32] C.H. Wang, H.C. Hsu, J.H. Hu, High-energy asymmetric supercapacitor based on petal-shaped $\mathrm{MnO}_{2}$ nanosheet and carbon nanotube-embedded polyacrylonitrile-based carbon nanofiber working at $2 \mathrm{~V}$ in aqueous neutral electrolyte, J. Power Sources 249 (2014) 1-8. https://doi.org/10.1016/j.jpowsour.2013.10.068.

[33] K. Xu, S.P. Ding, and T.R. Jow, Toward Reliable Values of Electrochemical Stability Limits for Electrolytes, J. Electrochem. Soc. 146 (1999) 4172-4178. https://doi.org/10.1149/1.1392609.

[34] K. Xu, M.S. Ding, T.R. Jow, A better quantification of electrochemical stability limits for electrolytes in double layer capacitors, Electrochim. Acta 46 (2001) 1823-1827. https://doi.org/10.1016/S0013-4686(01)00358-9.

[35] D. Weingarth, H. Noh, A. Foelske-Schmitz, A. Wokaun, R. Kötz, A reliable determination method of stability limits for electrochemical double layer capacitors, Electrochim. Acta 103 (2013) 119-124. https://doi.org/10.1016/j.electacta.2013.04.057.

[36] D. Weingarth, A. Foelske-Schmitz, R. Kötz, Cycle versus voltage hold - Which is the better stability test for electrochemical double layer capacitors?, J. Power Sources 225 (2013) 84-88. https://doi.org/10.1016/j.jpowsour.2012.10.019.

[37] D. Reber, R.-S. Kühnel and C. Battaglia, High-voltage aqueous supercapacitors based on NaTFSI, Sustainable Energy Fuels 1 (2017) 2155-2161. https://doi.org/10.1039/C7SE00423K.

[38] H. Wu, K. Lian, Aqueous based asymmetrical-bipolar electrochemical capacitor with a 2.4 V operating voltage, J. Power Sources 378 (2018) 209-215. https://doi.org/10.1016/j.jpowsour.2017.12.048.

[39] J. Jiang, B. Liu, G. Liu, D. Qian, C. Yang, J. Li, A systematically comparative study on $\mathrm{LiNO}_{3}$ and $\mathrm{Li}_{2} \mathrm{SO}_{4}$ aqueous electrolytes for electrochemical double-layer capacitors, Electrochim. Acta 274 (2018) 121-130. https://doi.org/10.1016/j.electacta.2018.04.097.

[40] S. Fleischmann, M. Widmaier, A. Schreiber, H. Shim, F.M. Stiemke, T.J.S. Schubert, V. Presser, High voltage asymmetric hybrid supercapacitors using lithium- and sodium-containing ionic liquids, Energy Storage Materials 16 (2019) 391-399. https://doi.org/10.1016/j.ensm.2018.06.011. 
[41] C.V. Mazzocchia, M. Bestetti, D. Acierno, A. Tito, A process for the preparation of a catalyst, a catalyst obtained thereby, and its use in the production of nanotubes, EP2213369A1, 2010.

[42] W.S. Hummers, R.E. Offeman, Preparation of Graphitic Oxide, J. Am. Chem. Soc. 80 (1958) 1339. https://doi.org/10.1021/ja01539a017.

[43] M. Hashempour, A. Vicenzo, M. Bahdanchyk, M. Bestetti, Parameters influencing the capacitive behavior of carbon composite electrodes: composition, morphology, electrical conductivity, and surface chemistry, J. Solid State Electrochem. 22 (2018) 3895-3911. https://doi.org/10.1007/s10008-018-4095-8.

[44] S. Dsoke, X. Tian, C. Täubert, S. Schlüter, M. Wohlfahrt-Mehrens, Strategies to reduce the resistance sources on Electrochemical Double Layer Capacitor electrodes, J. Power Sources 238 (2013) 422-429. https://doi.org/10.1016/j.jpowsour.2013.04.031.

[45] A. Laheäär, P. Przygocki, Q. Abbas, F. Béguin, Appropriate methods for evaluating the efficiency and capacitive behavior of different types of supercapacitors, Electrochem. Commun. 60 (2015) 21-25. https://doi.org/10.1016/J.ELECOM.2015.07.022.

[46] B.A. Boukamp, A Linear Kronig-Kramers Transform Test for Immittance Data Validation, J. Electrochem. Soc. 142 (1995) 1885-1894. DOI: 10.1149/1.2044210.

[47] P. Trucano, R. Chen, Structure of graphite by neutron diffraction, Nature, 258 (1975) 136-137. https://doi.org/10.1038/258136a0.

[48] H. Lipson, A.R. Stokes, The Structure of Graphite, Proc. R. Soc. A Math. Phys. Eng. Sci. 181 (1942) 101-105. https://doi.org/10.1098/rspa.1942.0063.

[49] H.C. Schniepp, J.-L. Li, M.J. McAllister, H. Sai, M. Herrera-Alonso, D.H. Adamson, R.K. Prud'homme, R. Car, A. Dudley A. Saville, I.A. Aksay, Functionalized Single Graphene Sheets Derived from Splitting Graphite Oxide, J. Phys. Chem. B 110 (2006) 8535-8539. https://doi.org/10.1021/JP060936F.

[50] N. Wu, X. She, D. Yang, X. Wu, F. Su, Y. Chen, Synthesis of network reduced graphene oxide in polystyrene matrix by a two-step reduction method for superior conductivity of the composite, J. Mater. Chem. 22 (2012) 17254-17261. https://doi.org/10.1039/c2jm33114d.

[51] Y.D. Kondrashev, A.I. Zaslavskii, The structure of the modifications of manganese dioxide, Izvestiya Akademii Nauk SSSR 15 (1951) 179-186. 
[52] H.F. McMurdie, E. Golovato, Study of the modifications of manganese dioxide, J. Res. Natl. Bur. Stand. 41 (1948) 589-600. https://doi.org/10.6028/jres.041.046.

[53] M. He, K. Fic, E. Frąckowiak, P. Novák, E.J. Berg, Ageing phenomena in highvoltage aqueous supercapacitors investigated by in situ gas analysis, Energy Environ. Sci., 2016,9, 623-633. https://doi.org/10.1039/C5EE02875B.

[54] Q. Gao, L. Demarconnay, E. Raymundo-Piñero, F. Béguin, Exploring the large voltage range of carbon/carbon supercapacitors in aqueous lithium sulfate electrolyte, Energy Environ. Sci., 5 (2012) 9611-9617. https://doi.org/10.1039/C2EE22284A.

[55] X. Lu, W.-L. Yim, B.H.R. Suryanto, C. Zhao Electrocatalytic Oxygen Evolution at Surface-Oxidized Multiwall Carbon Nanotubes, J. Am. Chem. Soc. 137 (2015) 29012907. https://doi.org/10.1021/ja509879r.

[56] Y. Yi, G. Weinberg, M. Prenzel, M. Greiner, S. Heumann, S. Becker, R Schlögl, Electrochemical corrosion of a glassy carbon electrode, Catalysis Today 295 (2017) 32-40. https://doi.org/10.1016/j.cattod.2017.07.013.

[57] K. Jurewicz, E. Frackowiak, and F. Béguin, Appl. Phys. A, Towards the mechanism of electrochemical hydrogen storage in nanostructured carbon materials 78 (2004) 981987. https://doi.org/10.1007/s00339-003-2418-8.

[58] C. Peng, S. Zhang, X. Zhou, G.Z. Chen, Unequalisation of Electrode Capacitances for Enhanced Energy Capacity in Asymmetrical Supercapacitors. Energy Environ. Sci. 3 (2010) 1499-1502. https://doi.org/10.1039/c0ee00228c.

[59] M.H. Tahmasebi, K. Raeissi, M.A. Golozar, A. Vicenzo, M. Hashempour, M. Bestetti, Tailoring the pseudocapacitive behaviour of electrochemically deposited manganesenickel oxide films, Electrochim. Acta 190 (2016) 636-647. https://doi.org/10.1016/J.ELECTACTA.2015.12.146.

[60] M.H. Tahmasebi, A. Vicenzo, M. Hashempour, M. Bestetti, M.A. Golozar, K. Raeissi, Nanosized Mn-Ni oxide thin films via anodic electrodeposition: a study of the correlations between morphology, structure and capacitive behaviour, Electrochim. Acta 206 (2016) 143-154. https://doi.org/10.1016/J.ELECTACTA.2016.04.087.

[61] P. Ratajczak, K. Jurewicz, P. Skowron, Q. Abbas, F. Béguin, Effect of accelerated ageing on the performance of high voltage carbon/carbon electrochemical capacitors in salt aqueous electrolyte, Electrochim. Acta 130 (2014) 344-350. https://doi.org/10.1016/j.electacta.2014.02.140. 


\section{Figures}
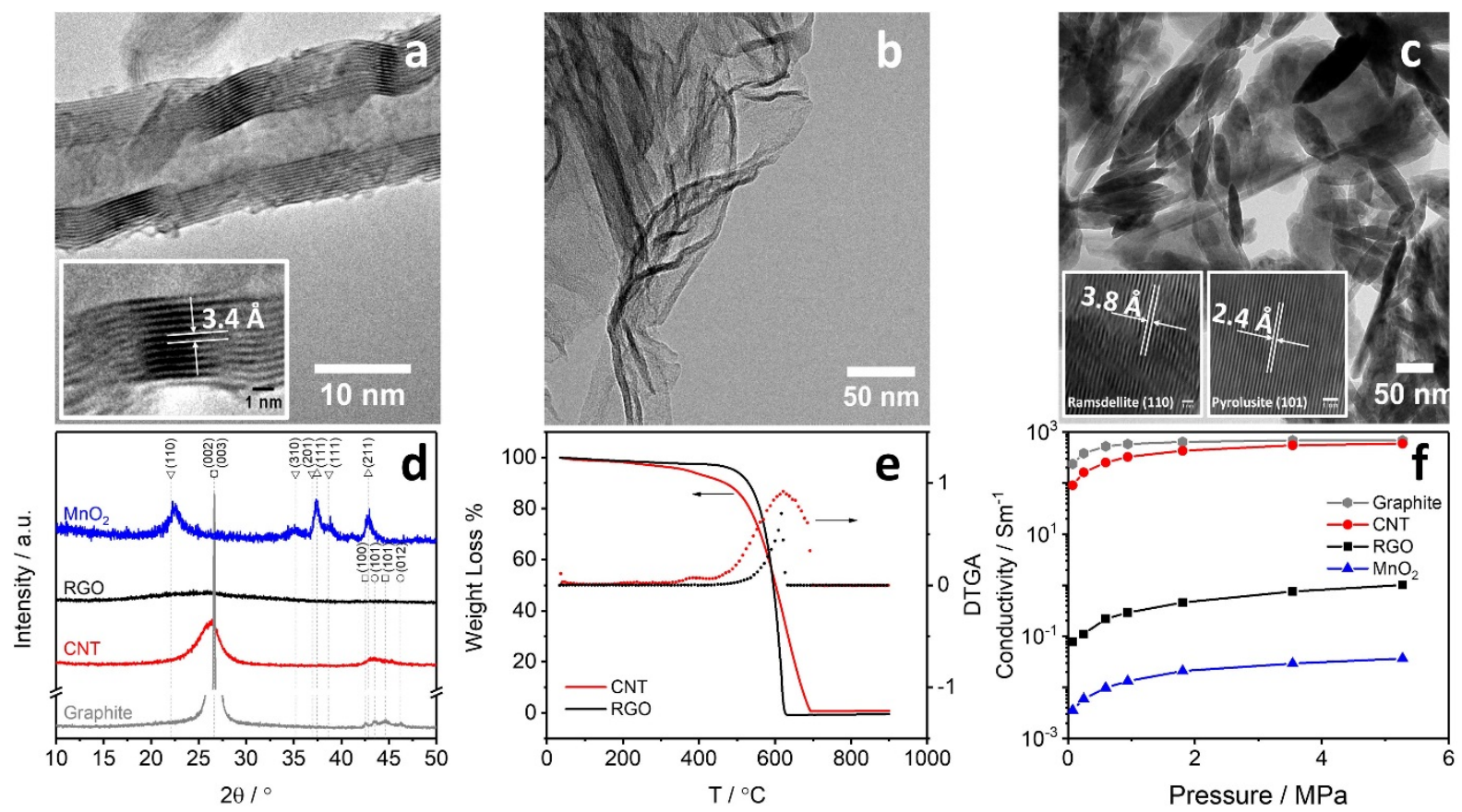

Fig. 1. TEM micrographs of (a) CNT (with HRTEM image in the inset), (b) RGO and (c) $\mathrm{MnO}_{2}$ powder (with HRTEM images in the insets); (d) XRD patterns of the same, as indicated, and graphite reference sample (O-Graphite $\mathrm{R} \overline{3} m, \square$-Graphite $\mathrm{P} 63 / m m c, \triangle-\mathrm{MnO}_{2}$ $\mathrm{P}_{2} / \mathrm{mnm}, \nabla-\mathrm{MnO}_{2}$ Pnam), (e) TGA of CNT and RGO, and (f) electrical conductivity measurements of the diverse materials, as indicated.
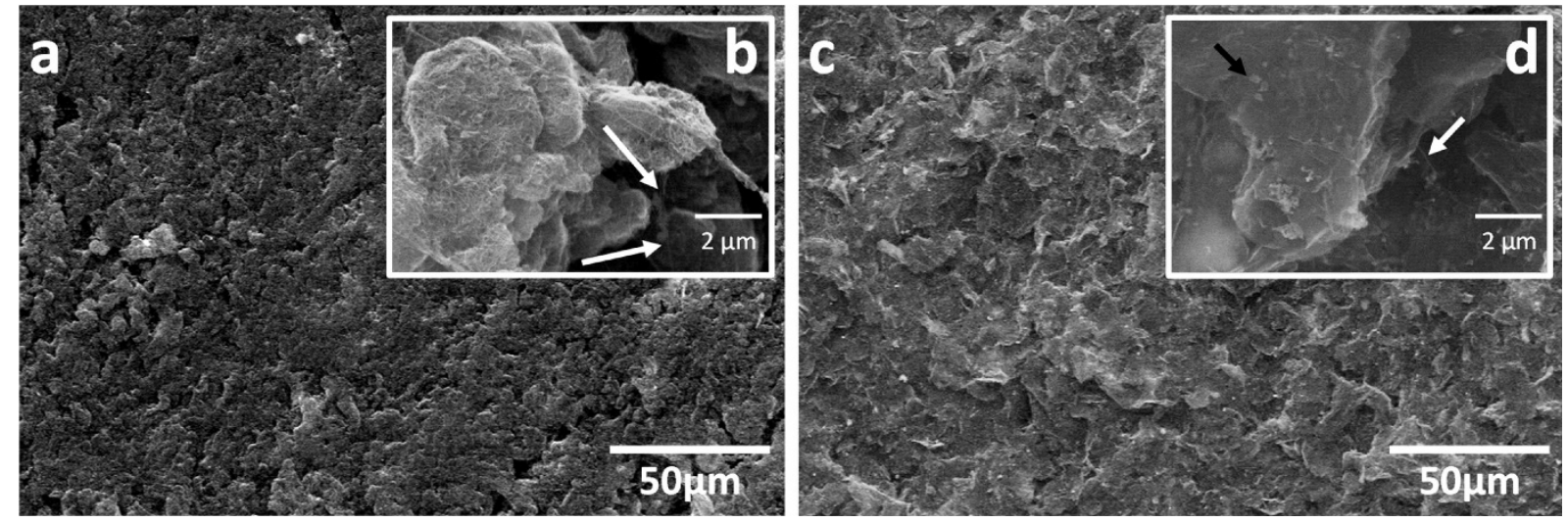

Fig. 2. SEM micrographs of: (a, b) CNT paste, and (c, d) M.RGO paste. 

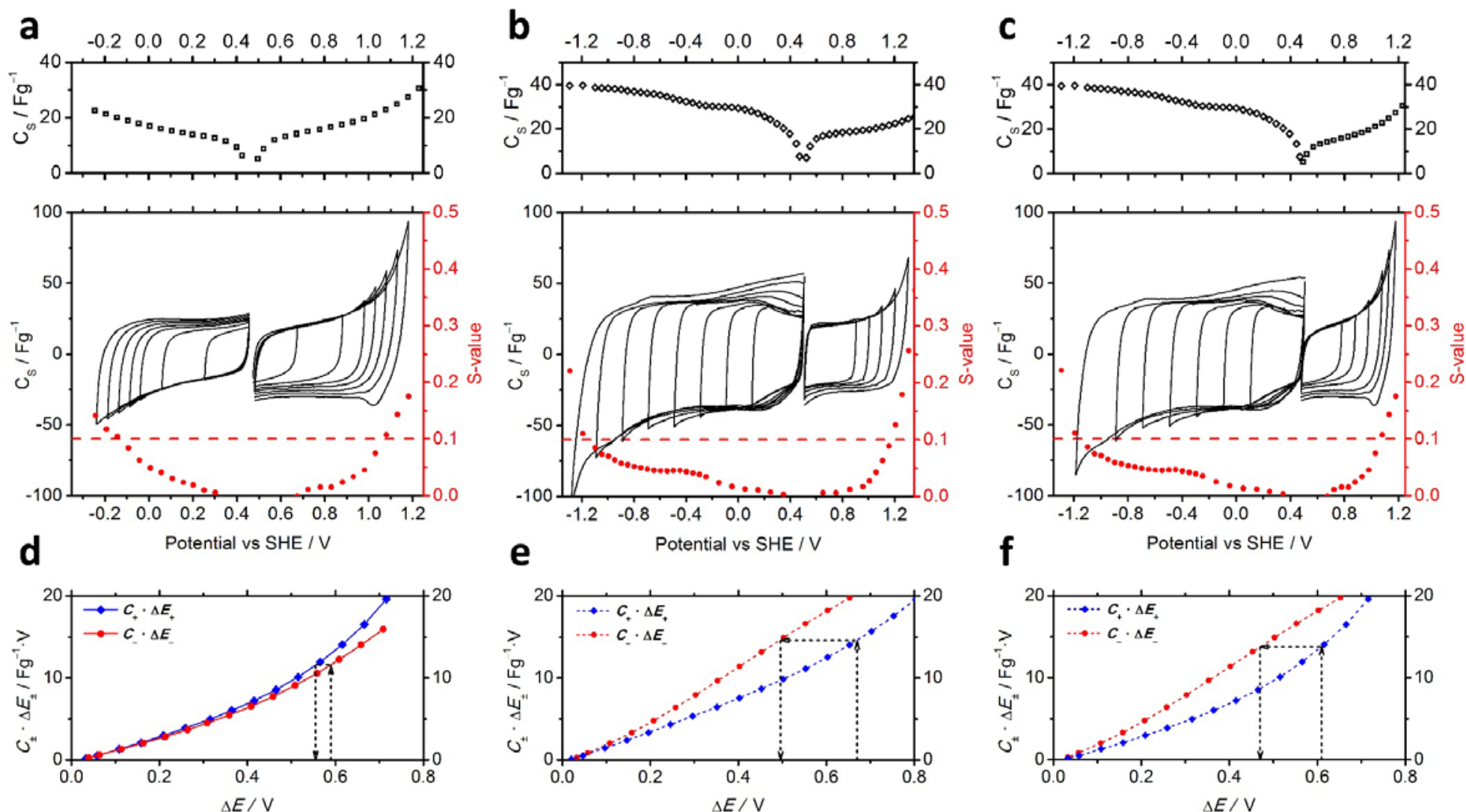

Fig. 3. CV curves at single electrodes at the scan rate of $5 \mathrm{mV} \mathrm{s}^{-1}$, corresponding S-value and specific capacitance $C_{s} v s$. potential for: (a) CNT electrode, and (b) M.RGO electrode, both in the positive and negative sweep direction; and (c) CNT and M.RGO electrodes, in the negative and positive sweep direction, respectively. The dashed line in the S-value plot visualizes the 0.1 threshold value criterion [33]. In the lower part of the figure, plots of the products $C_{-} \cdot \Delta E_{-}$and $C_{+} \cdot \Delta E_{+} v s . \Delta E$ for: (d) M.RGO cell, (e) CNT cell, and (f) ${ }^{-} C_{N T-M}$ RGO $^{+}$cell, illustrating the graphical method used to evaluate the PW of the cells with unit mass ratio $m_{+} / m_{-}$. The filled diamond symbol is used for the positive electrode, the filled circle for the negative. 

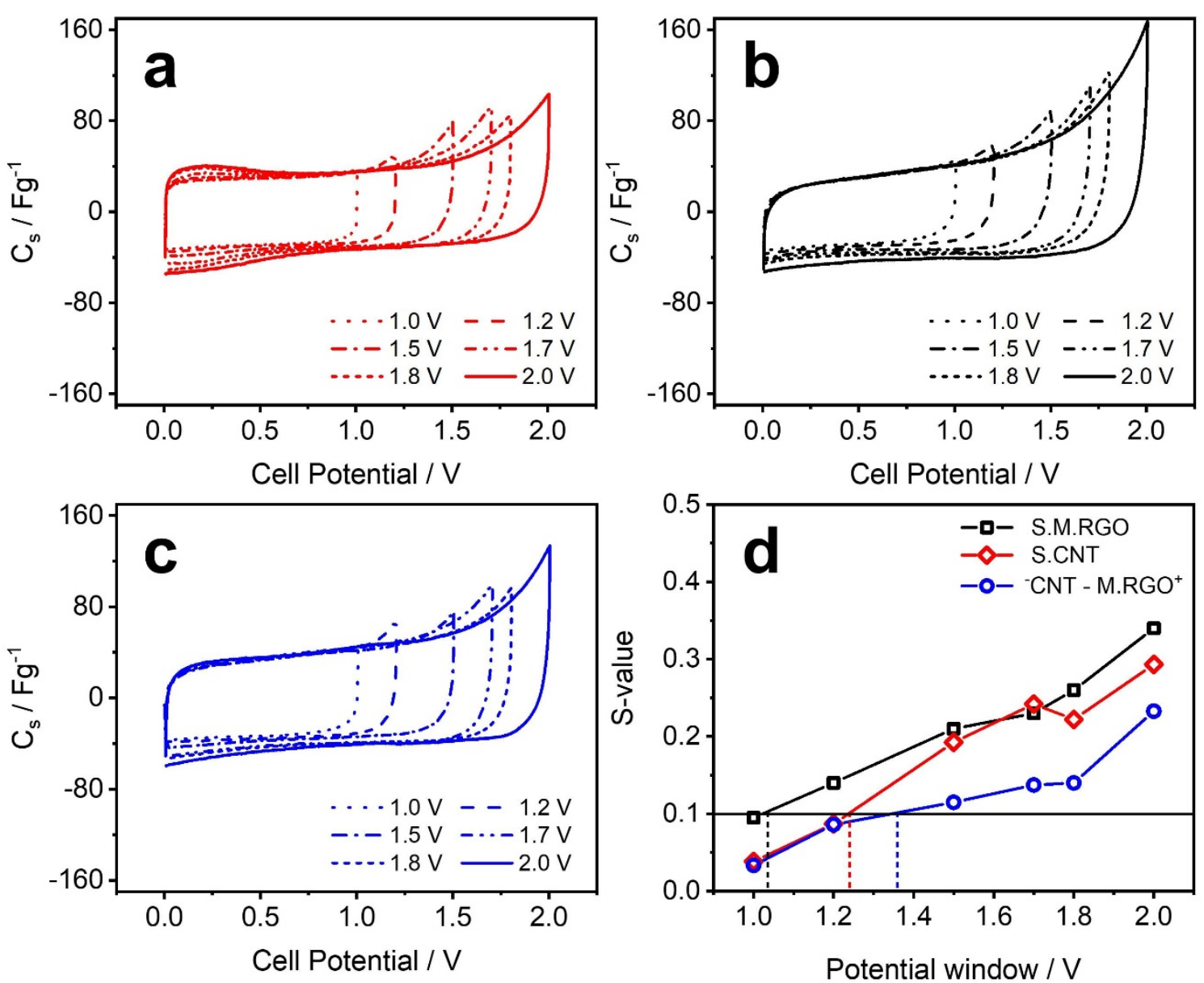

Fig. 4. Ciclic voltammetry curves of EC cells; (a) S.CNT, (b) S.M.RGO and (c) ${ }^{-}$CNTM.RGO ${ }^{+}$cell, performed at $5 \mathrm{mV} \mathrm{s}^{-1}$ over the PW from 1 to $2 \mathrm{~V}$; (d) plot of the $\mathrm{S}$ values derived by equation 2 , with the threshold line at 0.1 . 


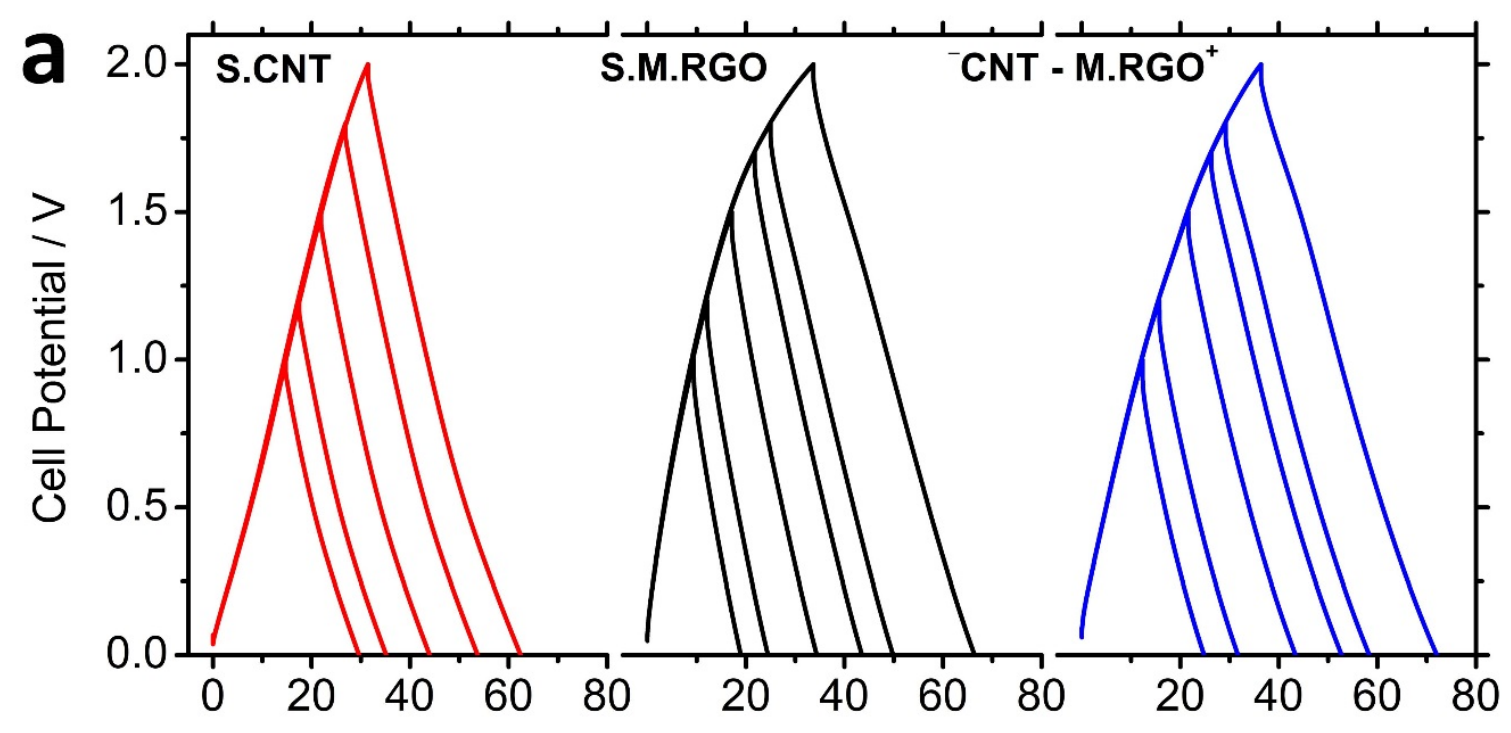

Time / s

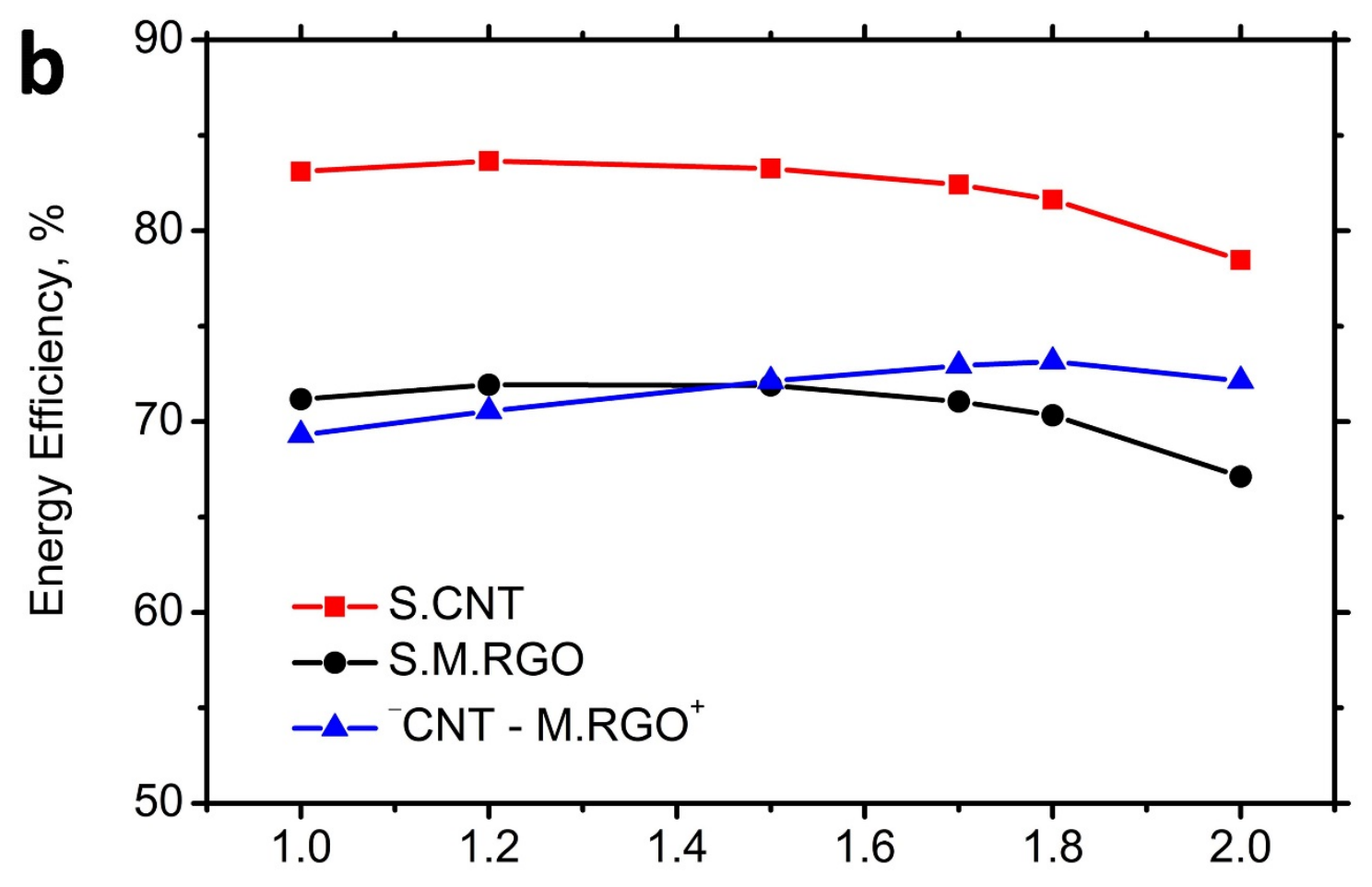

Cell Potential / V

Fig. 5. (a) Galvanostatic charge - discharge cycles of S.CNT, S.M.RGO and ${ }^{-C N T-M . R G O}{ }^{+}$ cells, at the charge - discharge rate of $1 \mathrm{~A} \mathrm{~g}^{-1}$, in a variable potential window, and (b) corresponding energy efficiency plot of the EC cells as a function of PW. 

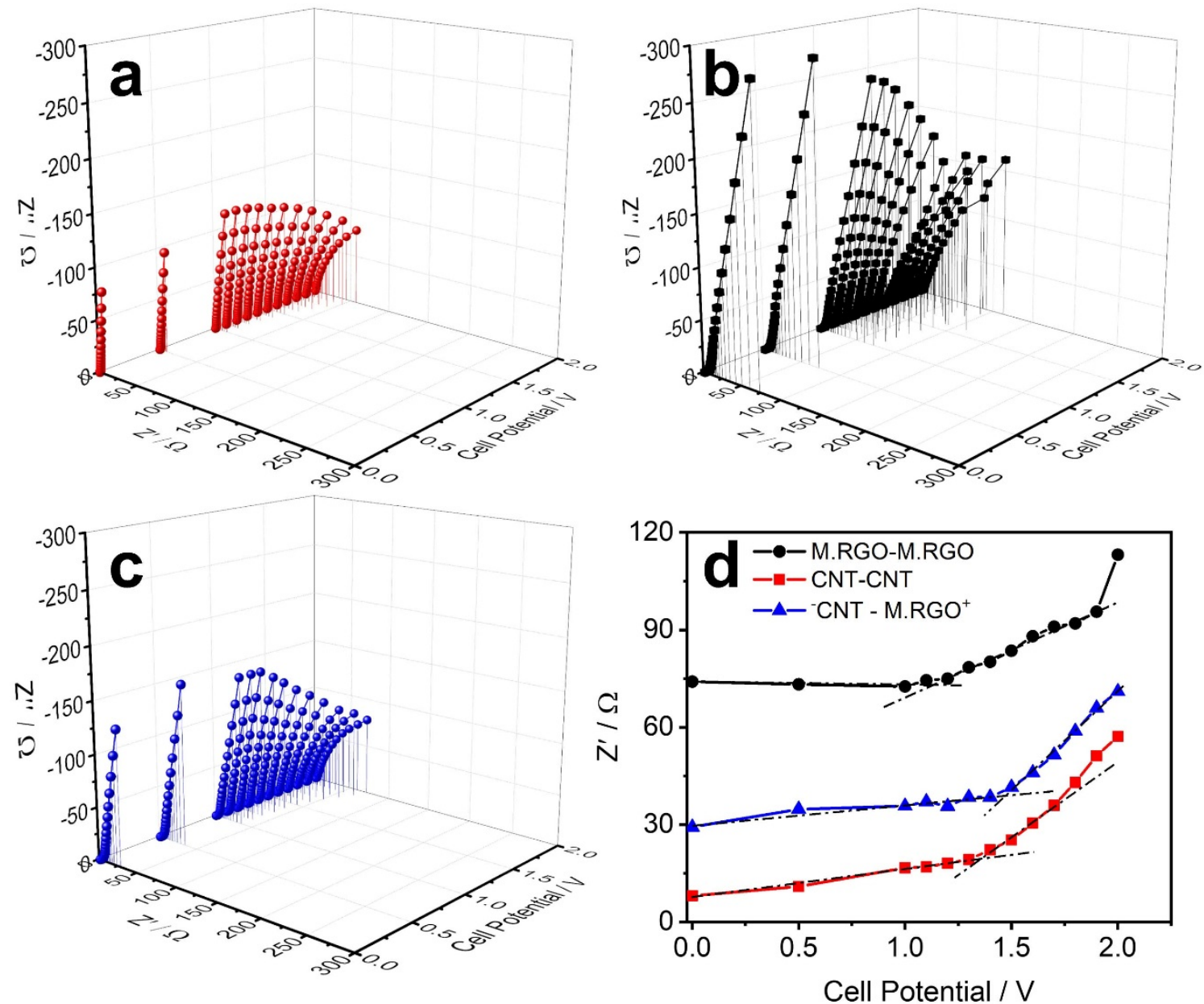

Fig. 6. Complex plots of the EC cells at varying applied potential, ranging from 0 (cell at open circuit) to $2 \mathrm{~V}$; (a) S.CNT, (b) S.M.RGO, and (c) ${ }^{-}$CNT-M.RGO ${ }^{+}$cell; (d) $Z^{\prime}{ }_{5 \mathrm{mHz}}$ as a function of the bias potential. 

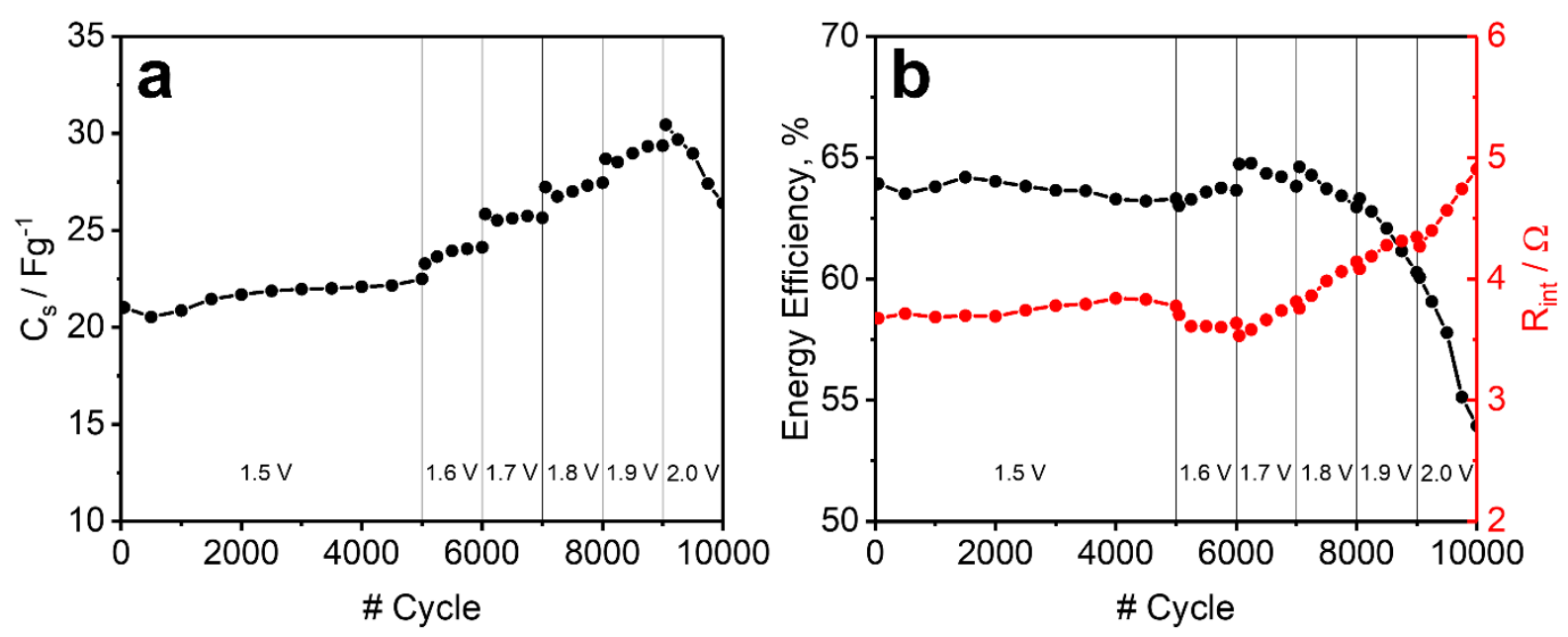

Fig. 7. Cycle life test of the ${ }^{-}$CNT-M.RGO ${ }^{+}$cell for 5000 cycles at $1.5 \mathrm{~V}$ and for 1000 cycles at each successive value of the PW increasing from $1.6 \mathrm{~V}$ to $2 \mathrm{~V}$ in step of $0.1 \mathrm{~V}$, as indicated: (a) specific capacitance and (b) energy efficiency and internal resistance vs. cycle number. 